\title{
Structural, Optical, and Electrical Studies on Pulse Plated AgInSe 2 Films
}

\author{
S. MURUGAN ${ }^{a}$ AND K.R. MURAli ${ }^{b, *}$ \\ ${ }^{a}$ Dept. of Physics, AVC College (Autonomous), Mannanpandal, Mayiladuthurai-609001, India \\ ${ }^{b}$ ECMS Division, CSIR-CECRI, Karaikudi, India \\ (Received September 13, 2012; in final form April 21, 2014)
}

\begin{abstract}
In this work, the pulse electrodeposition technique was employed for the first time to deposit $\mathrm{AgInSe}_{2}$ films. The films were deposited at room temperature from a bath containing Analar grade $10 \mathrm{mM}$ silver sulphate, $50 \mathrm{mM}$ indium sulphate and $5 \mathrm{mM} \mathrm{SeO}_{2}$. The deposition potential was maintained at $-0.98 \mathrm{~V}$ (SCE). Tin oxide coated glass substrates $(5.0 \Omega / \mathrm{sq})$ were used for depositing the films. The duty cycle was varied in the range of $6-50 \%$. The $\mathrm{X}$-ray diffraction pattern of the thin films deposited at different duty cycles indicated the peaks corresponding to $\mathrm{AgInSe}_{2}$. The transmission spectra exhibited interference fringes. Resistivity of the films increased from $1.5 \Omega \mathrm{cm}$ to $12.4 \Omega \mathrm{cm}$. Mobility increased with duty cycle. Carrier density decreased with duty cycle. The photovoltaic parameters of CdS/AgInSe 2 solar cells increased with duty cycle.
\end{abstract}

DOI: $10.12693 /$ APhysPolA.126.727

PACS: 68.55.ag, 73.61.Jc, 88.40.hj, 88.40.jn

\section{Introduction}

Ternary semiconductor compounds have attracted the technological interest owing to their promises for practical application in the areas of visible and infrared light emitting diodes, infrared detectors, optical parametric oscillators, nonlinear optics, solar cells, optical frequency conversion, second harmonic generation devices, and many other electro-optical devices [1-4]. In the production of stable and radiation resistant polycrystalline thin film photovoltaic solar cells, reasonably high power conversion efficiency values have been achieved by using the ternary chalcopyrite semiconductors as an absorber layer [5]. Ternary chalcopyrite compounds have photovoltaic potential for solar cells since their optical band gap lies between 0.8 and $2.0 \mathrm{eV}$ and they can be grown either $n$-or $p$-type [6]. Thin film solar cells made from ternary chalcopyrite compounds, such as $\mathrm{CuInSe}_{2}$ and its analogous alloys, have begun to fulfill the promise of low-cost, power generation from non-polluting, clean energy sources. $\mathrm{AgInSe}_{2}$ (AIS) is one of the potential candidates of this family of alloys due to its band gap around $1.2 \mathrm{eV}$ [6], which makes it ideal absorber material for solar cells. AgInSe 2 crystallizes in the chalcopyrite structure, which is closely related to the zinc blende structure. The commonly used methods for preparing silver indium selenide thin films are flash evaporation [7], rf magnetron sputtering [8], thermal evaporation [9-11], hot wall vacuum deposition [12], pulse laser deposition [13, 14], electrodeposition [15, 16] and co-evaporation [17]. The objective of the present work is to deposit silver indium selenide by the pulse electrodeposition technique and study their properties. To our knowledge this is the first report on pulse electrodeposited $\mathrm{AgInSe} \mathrm{S}_{2}$ films.

*corresponding author; e-mail: muraliramkrish@gmail.com

\section{Experimental methods}

$\mathrm{AgInSe}_{2}$ films were deposited by the pulse electrodeposition technique at room temperature from a bath containing Analar grade $10 \mathrm{mM}$ silver sulphate, $50 \mathrm{mM}$ indium sulphate and $5 \mathrm{mM} \mathrm{SeO}_{2}$. The deposition potential was maintained as $-0.98 \mathrm{~V}$ (SCE). Tin oxide $\left(\mathrm{SnO}_{2}\right)$ coated glass substrates $(5.0 \Omega / \mathrm{sq})$ was used for the deposition of the films. The duty cycle was varied in the range of $6-50 \%$. Thickness of the films measured by surface profilometer increased from $600 \mathrm{~nm}$ to $800 \mathrm{~nm}$ as the duty cycle decreased from $50 \%$ to $9 \%$. Structural characteristics was studied by using X'pert pro diffractometer using $\mathrm{Cu} K_{\alpha}(1.541 \AA)$ radiation from $40 \mathrm{kV}$ $\mathrm{X}$-ray source running at $30 \mathrm{~mA}$. Optical characteristics were studied by using U 3400 UV-VIS-NIR spectrophotometer. The surface morphology and roughness of the films were analyzed using a Nanoscope E-3138j AFM/ STM atomic force microscope (AFM).

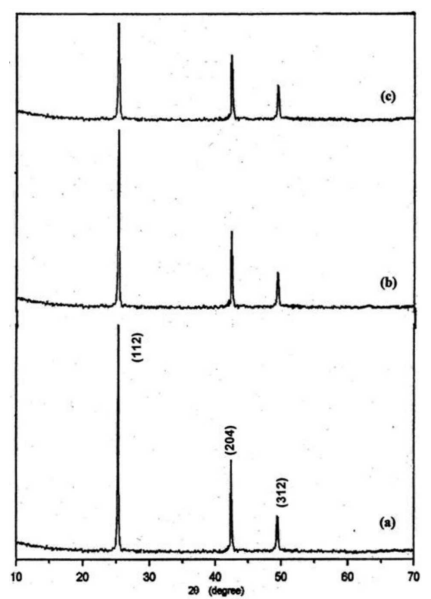

Fig. 1. XRD pattern of $\mathrm{AgInSe}_{2}$ films deposited at different duty cycles: (a) $9 \%$, (b) $33 \%$, (c) $50 \%$. 
In pulse electrodeposition $[18,19]$ the potential or current is alternated swiftly between two different values. This results in a series of pulses of equal amplitude, duration and polarity, separated by zero current. Each pulse consists of an ON-time $\left(T_{\mathrm{ON}}\right)$ during which potential and/current is applied, and an OFF-time $\left(T_{\mathrm{OFF}}\right)$ during which zero current is applied as shown in Fig. 1. It is possible to control the deposited film composition and thickness in an atomic order by regulating the pulse amplitude and width [20,21]. They favor the initiation of grain nuclei and greatly increase the number of grains per unit area resulting in finer grained deposit with better properties than conventionally plated coatings. The sum of the ON and OFF times constitute one pulse cycle. The duty cycle is defined as follows:

$$
\text { duty cycle }(\%)=\frac{\text { ON time }}{\text { ON time }+ \text { OFF time }} \times 100 \text {. }
$$

A duty cycle of $100 \%$ corresponds to conventional plating because OFF time is zero. In practice, pulse plating usually involves a duty cycle of $5 \%$ or greater. During the ON time the concentration of the metal ions to be deposited is reduced within a certain distance from the cathode surface. This so-called diffusion layer pulsates with the same frequency as the applied pulse current. Its thickness is also related to the current but reaches a limiting value governed primarily by the diffusion coefficient of the metal ions. During the OFF time the concentration of the metal ions builds up again by diffusion from the bulk electrolyte and will reach the equilibrium concentration of the bulk electrolyte if enough time is allowed. These variables result in two important characteristic features of pulse plating which make it useful for alloy plating as well as property changes as mentioned earlier.

(i) Very high instantaneous current densities and hence very high negative potentials can be reached. The high over potential causes a shift in the ratio of the rates of reactions with different kinetics. This high over potential associated with the high pulse current density greatly influences the nucleation rate because a high energy is available for the formation of new nuclei.

(ii) The second characteristic feature is the influence of the OFF time during which important adsorption and desorption phenomena as well as recrystallization of the deposit occurs.

Pulse plating technique has distinct advantages compared to conventional electrodeposition namely, crack free, hard deposits and fine grained films with more uniformity, lower porosity and better adhesion. It is well known that by using pulse current for electrodeposition of metals and alloys it is possible to exercise greater control over the properties of electrodeposits and to improve them by modifying their microstructures [22]. It has been reported that a significant reduction in internal stress could be obtained when pulse current was used, compared to the use of conventional direct current [23]. Pulsed electrodeposition improved the hardness compared to direct current deposits [24].

\section{Results and discussion}

The films deposited at different duty cycles were characterized by the X-ray diffraction (XRD) studies. All the reflections could be indexed as the chalcopyrite $\mathrm{AgInSe} \mathrm{I}_{2}$ with the lattice parameters $a=6.134 \AA, c=11.813 \AA$, which were very close to the reported data (JCPDS Cards, 35-1099). As the duty cycle increased, the intensity of the peaks increased. Peaks corresponding to the (112), (204), and (312) reflections were observed (Fig. 1). The height of the peak increased with duty cycle. No characteristic peaks of other impurities, such as $\mathrm{Ag}_{2} \mathrm{Se}$ or $\mathrm{In}_{2} \mathrm{Se}_{3}$, were detected in the patterns. The crystallite size was determined from Scherrer's equation [25]:

crystallite size $=0.9 \lambda /(\beta \cos \theta)$,

where $\lambda$ is the wavelength of $\mathrm{Cu} K_{\alpha}$ X-rays (1.541 $\AA$ ), $\beta$ is the full width at half maximum and $\theta$ is the Bragg angle. The crystallite size was found to vary in the range of 40 to $18 \mathrm{~nm}$ with increase of duty cycle. The trend of decreasing grain size with increasing duty cycle can be best explained by an increased number of nucleation sites caused by the higher overpotential at longer current on-times. The same behavior of increasing overpotential with duty cycle was also found during zinc deposition from a chloride-based electrolyte but at lower overpotential [26]. The formation of large grains at lower duty cycles (i.e. shorther ON time and longer OFF time) can also be explained by desorption of some loosely bound particles (deposited during the ON time) during the longer OFF times which activates the growth centers and results in grain growth. Also the adatoms at longer OFF times have sufficient time to migrate over the substrate surface and enhance the grain growth process.

The dislocation density $\delta$, defined as the length of dislocation lines per unit volume of the crystal has been evaluated using the formula [27]:

$$
\delta=1 / D^{2} \text {. }
$$

Microstructral parameters of $\mathrm{AgInSe}_{2}$ films deposited at different duty cycles.

\begin{tabular}{c|c|c|c|c|c|c}
\hline \hline $\begin{array}{c}\text { Duty } \\
\text { cycle } \\
{[\%]}\end{array}$ & $\begin{array}{c}\text { Thickness } \\
{[\mathrm{nm}]}\end{array}$ & \multicolumn{2}{|c|}{$\begin{array}{c}\text { Lattice } \\
\text { parameter }[\AA]\end{array}$} & \begin{tabular}{c} 
Grain \\
size \\
\cline { 3 - 4 }
\end{tabular} & $\begin{array}{c}\text { Strain } \\
{\left[\times 10^{-4}\right]}\end{array}$ & $\begin{array}{c}\text { Dislocation } \\
\text { density } \\
\left(\times 10^{15} \mathrm{~cm}^{-3}\right)\end{array}$ \\
\hline 50 & 650 & 6.127 & 11.809 & 18 & 2.59 & 3.08 \\
33 & 700 & 6.130 & 11.810 & 24 & 2.25 & 1.73 \\
15 & 760 & 6.132 & 11.812 & 31 & 1.98 & 1.04 \\
9 & 850 & 6.134 & 11.813 & 40 & 1.76 & 0.625
\end{tabular}

The microstructural parameters are presented in Table I. From the table it is observed that the dislocation density decreases with increase of grain size. Information on the particle size and strain for the $\mathrm{AgInSe}_{2}$ films was obtained from the full-width at half-maximum of the diffraction peaks. The full-width at half-maximum $b$ can be expressed as a linear combination of the contributions from the particle size, $D$ and strain, $\varepsilon$ through the relation [28]:

$$
\beta \cos \theta / \lambda=1 / D+\varepsilon \sin \theta / \lambda \text {. }
$$

The plot of $\beta \cos \theta / \lambda$ vs. $\sin \theta / \lambda$ allows us to determine both strain and particles size from slope and intercept of the graph. 
The estimated values for films deposited at different duty cycles are listed in Table I. The deviation in the lattice parameter values from the bulk value observed in the present case clearly suggests that the grains in the films are under stress. Such a behaviour can be attributed to the change of nature, deposition conditions and the concentration of the native imperfections developed in thin films. This results in either elongation or compression of the lattice and the structural parameters. The density of the film is therefore found to change considerably in accordance with the variations observed with the lattice constant values [29]. The grain size is observed to increase from about $18 \mathrm{~nm}$ to $40 \mathrm{~nm}$ with decrease of duty cycle. The stress developed at higher duty cycles is likely to be due to the formation of native defects developed from the lattice misfit or dislocations. The defects have a probability to migrate parallel to the substrate surface with the surface mobility greatly influenced by the duty cycle so that the films will have a tendency to expand and develop an internal tensile stress. This type of change in internal stress is always predominant by the observed recrystallization process in polycrystalline films. The stress relaxation is mainly considered as due to dislocation glides formed in the films. The decrease of internal stress may be attributed to a decrease in dislocation density. The reduction in the strain and dislocation density with decrease of duty cycle may be due to the reduction in concentration of lattice imperfections due to the improved crystallinity at lower duty cycles.

Composition of $\mathrm{AgInSe}_{2}$ films deposited TABLE II at different duty cycles.

\begin{tabular}{c|c|c|c|c}
\hline \hline Duty cycle [\%] & $\mathrm{Ag}$ [at.\%] & $\mathrm{In}$ [at.\%] & Se [at.\%] & $\mathrm{Ag} / \mathrm{In}$ \\
\hline 9 & 24.87 & 24.56 & 51.59 & 1.012 \\
15 & 24.89 & 24.99 & 50.12 & 0.995 \\
33 & 24.90 & 25.08 & 50.02 & 0.993 \\
50 & 24.90 & 25.10 & 50.00 & 0.992
\end{tabular}

Composition of the films was estimated by recording the energy dispersive X-ray spectroscopy (EDS) spectrum of the films deposited at different duty cycles (Table II). It is observed that films deposited at lower duty cycles were silver rich. For the films deposited at $9 \%$ duty cycle, the $\mathrm{Ag} / \mathrm{In}$ ratio was 1.012 . As the duty cycle increased, the films became indium rich. This is due to the fact that at higher duty cycles, more flux of indium ions are available for deposition compared to the flux of indium ions at lower duty cycles, which results in higher concentration of indium thus decreasing the $\mathrm{Ag} / \mathrm{In}$ ratio. Based on the defect chemistry model of ternary compounds [30], compositional deviations of the $\mathrm{AgInSe}_{2}$ can be expressed by non-stoichiometry parameter $(\Delta y=[2 \mathrm{Se} /(\mathrm{Ag}+3 \mathrm{In})]-1)$. The parameter $\Delta y$ is related to the electronic defects. For $\Delta y>0$, the film has a $p$-type conductivity and it has an $n$-type conductivity for $\Delta y<0$. In this study the value of $\Delta y$ is greater than zero and the films exhibit $p$-type conductivity.

Insight on the surface topography was made using AFM micrographs. The AFM images of the $\mathrm{AgInSe}_{2}$

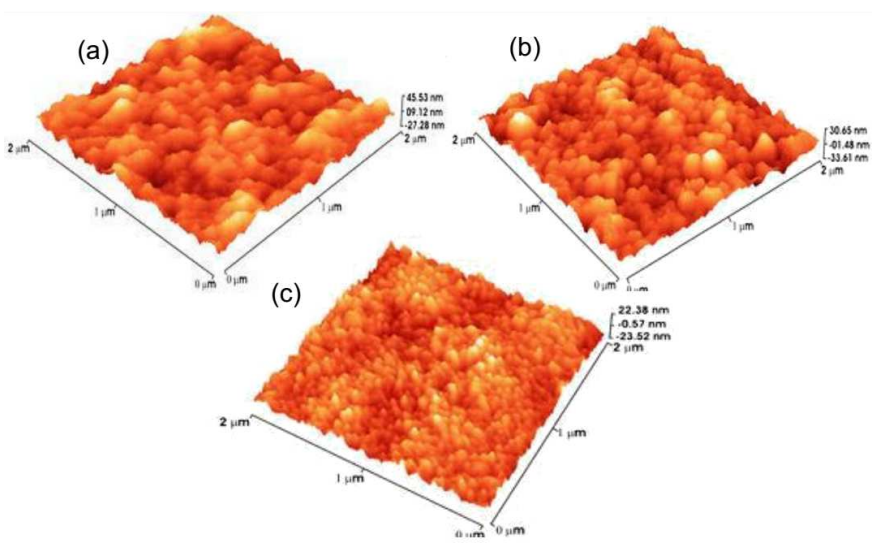

Fig. 2. Atomic force micrographs of $\mathrm{AgInSe}_{2}$ films deposited at different duty cycles: (a) $9 \%$, (b) $33 \%$, (c) $50 \%$.

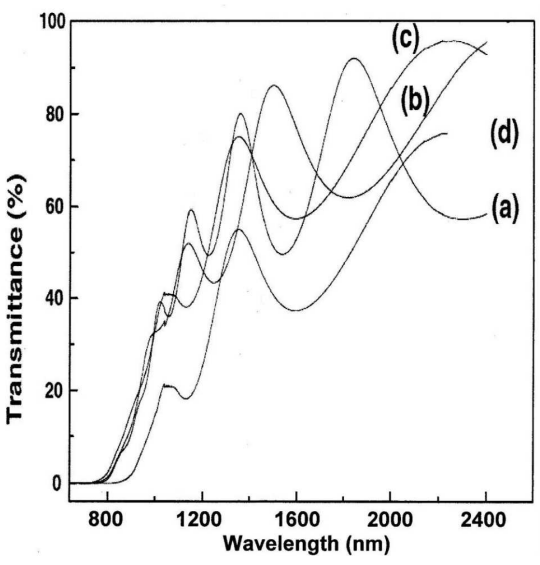

Fig. 3. Transmission spectra of $\mathrm{AgInSe}_{2}$ films deposited at different duty cycles: (a) $50 \%$, (b) $33 \%$, (c) $15 \%$, (d) $9 \%$.

films deposited at different duty cycles are shown in Fig. 2. These images give a clear understanding about the topographical changes in the films. It shows that the films are composed of nanoparticles and the films' surfaces are condensed, uniform and smooth. The decrease in duty cycle increases rms value of surface roughness from $0.35 \mathrm{~nm}$ to $1.56 \mathrm{~nm}$ on the AFM images due to the increase of grain size. The grains become larger as the duty cycle is decreased. This is also supported by the $\mathrm{X}$-ray diffraction data.

Figure 3 shows the room temperature transmittance spectra of $\mathrm{AgInSe}_{2}$ thin films deposited at different duty cycles. Interference can be observed in all samples. The value of the refractive index was calculated by the envelope method using the following relations:

$$
n=\left[N_{1}+\left(N_{1}^{2}+s^{2}\right)^{1 / 2}\right]^{1 / 2},
$$
where

$$
N_{1}=2 s\left[\left(T_{\mathrm{M}}-T_{\mathrm{m}}\right) / T_{\mathrm{M}} T_{\mathrm{m}}\right]+\left(s^{2}+1\right) / 2 .
$$

$T_{\mathrm{M}}$ and $T_{\mathrm{m}}$ are the values of maximum and minimum transmission values at a particular wavelength, " $s$ " is the 
refractive index of the substrate. Refractive index can be estimated by extrapolating envelopes corresponding to $T_{\mathrm{M}}$ and $T_{\mathrm{m}}$. These fringes can be used to calculate the refractive index $(n)$ of the thin films using the above equations. The refractive indexes corresponding to $T_{\mathrm{M}}$ and $T_{\mathrm{m}}$ for the same wavelengths are calculated. The refractive index varied in the range of 2.302 to 2.313 with increase of duty cycle. The variation of refractive index with wavelength is shown in Fig. 4. The refractive index values agree with earlier report [31].

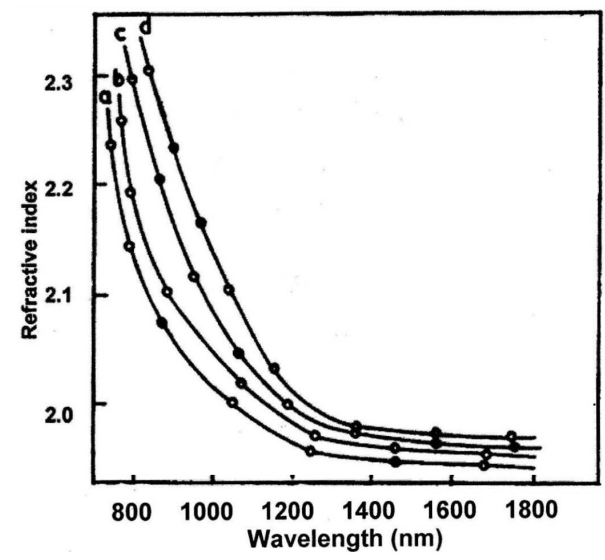

Fig. 4. Variation of refractive index with wavelength of AgInSe ${ }_{2}$ films deposited at different duty cycles: (a) $9 \%$, (b) $15 \%$, (c) $33 \%,(d) 50 \%$.

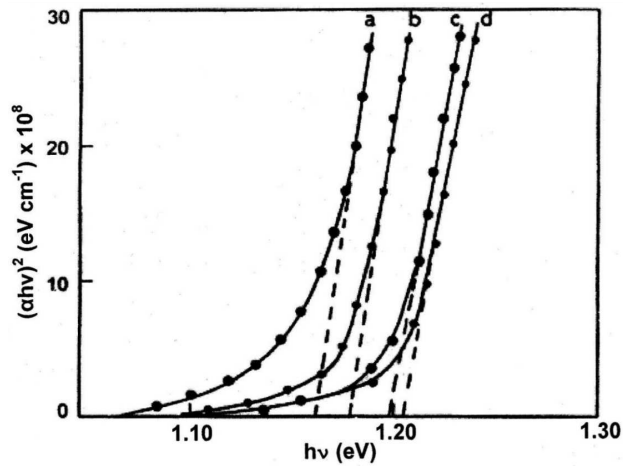

Fig. 5. $(\alpha h \nu)^{2}$ vs. $h \nu$ plot of $\mathrm{AgInSe}_{2}$ films deposited at different duty cycles: (a) $9 \%$, (b) $15 \%$, (c) $33 \%$, (d) $50 \%$.

Figure 5 shows photon energy vs. $(\alpha h \nu)^{2}$ plot of $\mathrm{AgInSe}_{2}$ thin films deposited at different duty cycles, with $\alpha$ and $h \nu$ being the absorption coefficient and photon energy, respectively. Bandgap energy $\left(E_{\mathrm{g}}\right)$ can be calculated using the following equation for estimating the absorption coefficient $(\alpha)$ :

$$
\alpha=A / h \nu\left(h \nu-E_{\mathrm{g}}\right)^{1 / 2} .
$$

A bandgap energy in the range of $1.16-1.21 \mathrm{eV}$ was obtained using $\alpha h \nu=0$. This value is comparable with the previous reports of $1.21 \mathrm{eV}[14]$. The lower values of band gap obtained at $10 \%$ duty cycle is due to the slight excess of silver in these films. The indium concentration increases gradually with increase of duty cycle and hence the band gap value increases from $1.16 \mathrm{eV}$ to $1.21 \mathrm{eV}$. This is supported by energy dispersive spectroscopy (EDAX) data.

TABLE III

Transport parameters of $\mathrm{AgInSe}_{2}$ films deposited at different duty cycles.

\begin{tabular}{c|c|c|c}
\hline \hline $\begin{array}{c}\text { Duty cycles } \\
{[\%]}\end{array}$ & $\begin{array}{c}\text { Resistivity } \\
{[\Omega \mathrm{cm}]}\end{array}$ & $\begin{array}{c}\text { Mobility } \\
{\left[\mathrm{cm}^{2} \mathrm{~V}^{-1} \mathrm{~s}^{-1}\right]}\end{array}$ & $\begin{array}{c}\text { Carrier density } \\
{\left[\mathrm{cm}^{-3}\right] \times 10^{16}}\end{array}$ \\
\hline 9 & 2.8 & 34.1 & 6.54 \\
15 & 4.7 & 30.2 & 4.39 \\
33 & 8.6 & 27.1 & 2.67 \\
50 & 12.4 & 23.8 & 2.12
\end{tabular}

The room temperature transport parameters were measured by Hall-Van der Pauw technique by providing gold ohmic contact. The influence of duty cycle on the resistivity of the films is shown in Table III. The films exhibit $p$-type conductivity. The EDAX results support the $p$-type conductivity, since the non-stochiometry parameter is greater than zero. The magnitude of the resistivity increased from $0.10 \Omega \mathrm{cm}$ to $3.67 \Omega \mathrm{cm}$ as the duty cycle is increased. The resistivity values are lower than earlier report [32]. The variation in resistivity with duty cycle can be explained in terms of the $\mathrm{Ag} / \mathrm{In}$ ratio obtained from EDAX measurements. At low duty cycles, a high $\mathrm{Ag} / \mathrm{In}$ ratio is observed. At higher duty cycle, $\mathrm{Ag} / \mathrm{In}$ ratio is less than unity, hence as the concentration of silver decreases, the resistivity increases. The variation of room temperature mobility and carrier density with duty cycle is also shown in Table II. The increase of resistivity at $50 \%$ duty cycle can also be explained in terms of the decrease of carrier density with increase of duty cycle. The values of mobility and carrier density decrease with increase of duty cycle. Mobility and carrier density values are higher than in earlier report [32].

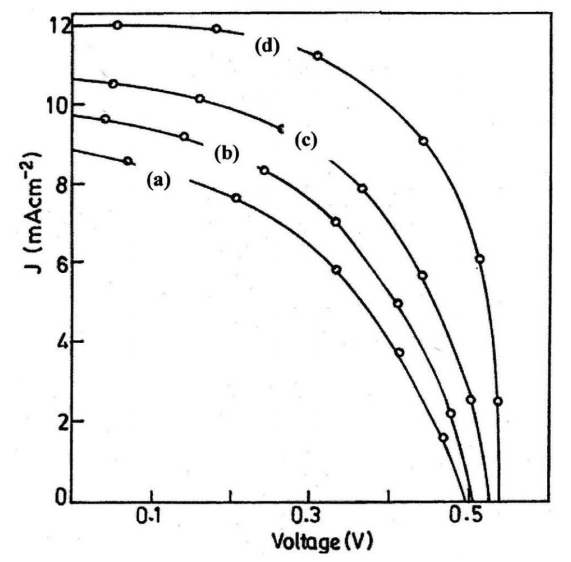

Fig. 6. Photovoltaic characteristics of $\mathrm{CdS} / \mathrm{AgInSe}_{2}$ solar cells fabricated with $\mathrm{AgInSe}_{2}$ films deposited at different duty cycles: (a) $50 \%,(b) 33 \%,(c) 15 \%,(d) 9 \%$. 
TABLE IV

Photovoltaic parameters of $\mathrm{CdS} / \mathrm{AgInSe}_{2}$ fabricated with $\mathrm{AgInSe}_{2}$ films deposited at different duty cycles (illumination $-100 \mathrm{~mW} \mathrm{~cm}^{-2}$ ).

\begin{tabular}{c|c|c|c|c|c|c}
\hline \hline $\begin{array}{c}\text { Duty } \\
\text { cycles [\%] }\end{array}$ & $\begin{array}{c}V_{\text {oc }} \\
{[\mathrm{V}]}\end{array}$ & $\begin{array}{c}J_{\mathrm{sc}} \\
{\left[\mathrm{mA} \mathrm{cm}^{-2}\right]}\end{array}$ & $\mathrm{FF}$ & $\begin{array}{c}\eta \\
{[\%]}\end{array}$ & $\begin{array}{c}R_{\mathrm{s}} \\
{[\Omega]}\end{array}$ & $\begin{array}{c}R_{\mathrm{sh}} \\
{[\mathrm{k} \Omega]}\end{array}$ \\
\hline 50 & 0.49 & 9.0 & 0.40 & 1.74 & 50 & 1.10 \\
33 & 0.50 & 9.7 & 0.50 & 2.40 & 45 & 1.20 \\
15 & 0.52 & 10.8 & 0.51 & 2.88 & 40 & 1.15 \\
9 & 0.53 & 12.0 & 0.71 & 4.54 & 28 & 1.90
\end{tabular}

The current-voltage characteristics of the $\mathrm{AgInSe}_{2}$ based solar cells with $n$-CdS is shown in Fig. 6. The solar cell parameters, open circuit voltage $\left(V_{\text {oc }}\right)$, short circuit current $\left(I_{\mathrm{sc}}\right)$, series resistance $\left(R_{\mathrm{s}}\right)$, shunt resistance $\left(R_{\mathrm{sh}}\right)$, and fill factor $(\mathrm{FF})$ are given in Table IV. From Table IV, it is clear that as the duty cycle for deposition of $\mathrm{AgInSe}_{2}$ decreased, the photo output increased. Arya et al. [33] have reported that the low value of open circuit voltage in $\mathrm{CuInSe}_{2} / \mathrm{CdS}$ solar cells is due to the exposure of $\mathrm{CuInSe}_{2}$ to atmosphere before CdS deposition. In our case, after the deposition of each layer, the films are taken out. There is every possibility for the formation of a thin insulating layer at the interface. Further, the short circuit current density is low due to the high series resistance. This may be the reason for the low efficiency of the fabricated solar cells.

\section{Conclusions}

This study clearly illustrates that the pulse plating technique can be employed for the deposition of nanocrystalline $\mathrm{AgInSe}_{2}$ films. Films with transmission around $80 \%$ can be prepared. Films possessing resistance around $12 \Omega$ can be prepared. Solar cells fabricated with $\mathrm{AgInSe}_{2}$ films deposited at $9 \%$ duty cycle and CdS films exhibiting a $V_{\mathrm{oc}}$ of $0.53 \mathrm{~V}, J_{\mathrm{sc}}$ of $12 \mathrm{~mA} \mathrm{~cm}^{-2}, \mathrm{FF}$ of 0.71 , and efficiency of $4.54 \%$ can be prepared.

\section{References}

[1] J.L. Shay, J.H. Wernick, Ternary Chalcopyrite Semiconductors: Growth, Electronic Properties, and Applications, Pergamon Press, New York 1975.

[2] U.N. Roy, Y. Cui, R. Hawrami, A. Burger, L. Orona, J.T. Goldstein, Solid State Commun. 139, 527 (2006).

[3] S.H. You, K.J. Hong, T.S. Jeong, C.J. Youn, J.S. Park, D.C. Shin, J.D. Moon, J. Appl. Phys. 95, 4042 (2004).

[4] P.G. Schunemann, S.D. Setzler, T.M. Pollak, M.C. Ohmer, J.T. Goldstein, D.E. Zelmon, J. Cryst. Growth 211, 242 (2000).

[5] H. Neumann, Cryst. Res. Technol. 39, 939 (2004).

[6] B. Tell, J.T. Shay, H.M. Kasper, J. Appl. Phys. 43, 2469 (1972).
[7] M.A. Contreras, B. Egaas, K. Ramanathan, J. Hiltner, A. Swartzlander, F. Hasoon, R. Noufi, Prog. Photovolt. Res. Appl. 7, 311 (1999).

[8] P.P. Ramesh, S. Uthanna, B.S. Naidu, P.J. Reddy, Thin Solid Films 292, 290 (1997).

[9] R.D. Weir, P.E. Jessop, B.K. Garside, Can. J. Phys. 65, 1033 (1987).

[10] A. El-Korashy, M.A. Abdel-Rahim, H. El-Zahed, Thin Solid Films 338, 207 (1999).

[11] H. El Zahed, J. Phys. Chem. Solids 62, 641 (2001).

[12] K. Yoshino, H. Matsuo, M. Yamauchi, K. Morimoto, Phys. Status Solidi C 6, 1067 (2009).

[13] D. Pathak, R.K. Bedi, D. Kaur, Mater. Manufact. Process 25, 1012 (2010).

[14] D. Pathak, R.K. Bedi, A. Kaushal, D. Kaur, Int. J. Mod. Phys. B 24, 5379 (2010).

[15] H. Mustafa, D. Hunter, A.K. Pradhan, U.N. Roy, Y. Cui, A. Burger, Thin Solid Films 515, 7001 (2007).

[16] D. Raviendra, J.K. Sharma, Phys. Status Solidi A 88, 365 (1985).

[17] Y. Ueno, Y. Kojima, T. Sugiura, H. Minoura, Thin Solid Films 91, 189 (1990).

[18] M. Ghaemi, L. Binder, J. Power Sources 111, 248 (2002).

[19] A. Marlot, P. Kern, D. Landolt, Electrochim. Acta 48, 29 (2002).

[20] S. Kainuma, S. Ishikura, K. Hisatake, J. Magn. Soc. Jpn. 21, 889 (1995).

[21] T. Houga, A. Yamada, Y. Ueda, J. Jpn. Inst. Met. 64, 739 (2000).

[22] M.E. Bahrololoom, R. Sani, Surf. Coat. Technol. 192, 154 (2005).

[23] K.M. Yin, Surf. Coat. Technol. 88, 162 (1996).

[24] G. Devaraj, S.K. Seshadri, Plat. Surf. Finish. 83, 62 (1996).

[25] P. Scherrer, Gott. Nachr. 2, 98 (1918).

[26] K.M. Youssef, P.S. Fedkiw, C.C. Koch, J. Electrochem. Soc. 151, C103 (2004).

[27] G.B. Williamson, R.C. Smallman, Philos. Mag. 1, 34 (1956).

[28] S.B. Qadri, E.F. Skelton, D. Hsu, A.D. Dinsmore, J. Yang, H.F. Gray, B.R. Ratna, Phys. Rev. B 60, 9191 (1999)

[29] M. El.Sherrif, F.S. Terra, S.A. Khodier, J. Mater Sci. Mater. Electron. 7, 391 (1996).

[30] J.A. Groenik, P.H. Janse, Z. Phys. Chem. 110, 17 (1978).

[31] M.C. Santhosh Kumar, B. Pradeep, Ind. J. Phys. 85, 401 (2011)

[32] Y. Ema, N. Harakawa, Jpn. J. Appl. Phys. 34, 3260 (1995).

[33] R.R. Arya, T. Warminski, R. Beaulieu, M. Kwietniak, W. Loferskii, J.J. Giriat, Sol. Energy Mater. 8, 471 (1983). 